\title{
Thermo-Mechanical Autofrettage Process of Spherical Vessel
}

\author{
Rupali
}

\begin{abstract}
In this analysis results of Elastic-plastic stress distributions in a spherical pressure vessel with ThermoMechanical loads are discussed. Results of study are obtained with Finite element (FE) analysis. A quarter of pressure vessel is considered and modeled with all realistic details. In addition to presenting the stress distribution of the pressure vessel, in this work the effects thermo-Mechanical autofrettage on different limit strength for spherical pressure vessels are investigated. The effect of changing the load and various geometric parameters is investigated. Consequently, it can be observed that to be the significant differences between the present thermo-Mechanical autofrettage and earlier (Mechanical autofrettage and Thermal autofrettage) method of autofrettage for the predictions of Elastic-plastic stress distributions of spherical pressure vessels. Some realistic examples are considered and results are obtained for the whole vessel by applying thermal load and mechanical load. The actual material curve is used for loading, unloading and residual stress behavior of spherical pressure vessel. Kinematic hardening material is considered and effect of Bauschinger effect factors are studied with thermo-mechanical load. Equivalent Von -Mises yield criteria is used for yield criteria. Behavior of elastic-perfectly plastic is also studied and compared. Influence of Thermo-Mechanical autofrettage over stress distribution and load bearing capacity of spherical vessel is examined. The question of whether Thermo-mechanical autofrettage gives more favorable residual compressive stress distribution and therefore extension of pressure vessel life is investigated in this analysis.
\end{abstract}

Keywords: Thermo-Mechanical Autofrettage, Strain hardening, Tangent modulus, FE Analysis, Residual stress.

\section{INTRODUCTION}

There have been bountiful study on the analysis of residual stresses and deformation for thick-walled cylindrical and spherical vessel subjected to Autofrettage process[1-21]and Re- autofrettage process [22-24].Some researchers [25-30] further extended their work for Fatigue life of autofrettaged vessels. Thermal stress analysis of cylindrical vessels and spherical vessels for elastic range were discussed by several authors [31-33].It is observed that most of the previous work related to Autofrettage had been done based on the mechanical load. The only paper of Dixit and Kamal [34] presented the feasibility of thermal autofrettage of thick wall

Revised Manuscript Received on February 10, 2020.

* Correspondence Author

Rupali*, Mechanical Engineering Department, Dr. B.C.Roy Engineerng College, Durgapur, India. Email: rupaandme@rediffmail.com

(C) The Authors. Published by Blue Eyes Intelligence Engineering and Sciences Publication (BEIESP). This is an open access article under the CC BY-NC-ND license (http://creativecommons.org/licenses/by-nc-nd/4.0/) cylinder in 2015.Research in thermal autofrettage analysis and design optimization of autofrettaged sphere had not been received proper attention by the research community. Residual stresses of spherical vessel by thermal loading have been obtained by Rupali. al. [35]. The present work present fundamental investigation on residual stress distribution of spherical vessel subjected to thermo-mechanical combined autofrettage processes under thermo-mechanical loading conditions.

\section{THEORETICAL CONCEPT}

The elastic stresses for the combined loading problem are simply a superposition of the elastic stresses in the innersurface pressurization problem. If an internal pressure $P$ is applied along with the thermal gradient, the stresses in the elastic sphere are expressed by the sum of Mechanical stress and thermal stress. Fig. 1 shows loading and unloading of a Kinematic hardening material. The radial and tangential stresses for sphere $\sigma_{r}$ and $\sigma_{t}$ must satisfy the equilibrium equation,

$$
\frac{d \sigma_{r}}{d r}-\frac{2\left(\sigma_{t}-\sigma_{r}\right)}{r}=0 \ldots \ldots \ldots \ldots
$$

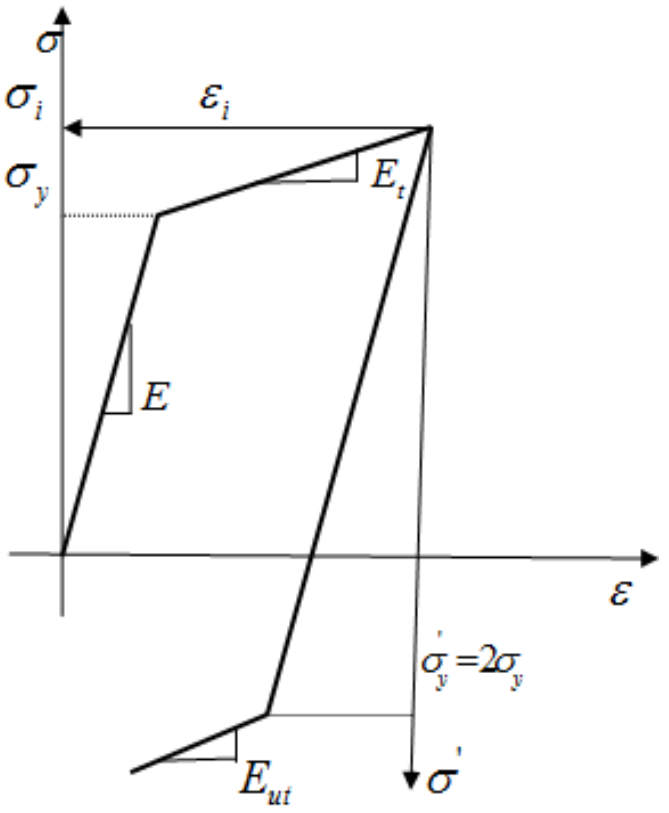

Fig. 1 Stress Strain diagram : kinematic hardening The residual stress distribution for Mechanical laod and Thermal load can be determined by using loading stress minus corresponding unloading stress, i.e., $\sigma_{\text {Residual }}=\sigma_{\text {loading }}-\sigma_{\text {unloading }}$ 
Now,

The total residual stresses are the summation of thermal and mechanical residual stresses. So, total residual radial and total residual tangential stresses are ,

$$
\begin{gathered}
\sigma_{r_{\text {Total }}}=\sigma_{r_{\text {thermal }}}+\sigma_{r_{\text {Mechanical }}} \\
\sigma_{t_{\text {Total }}}=\sigma_{t_{\text {thermal }}}+\sigma_{t_{\text {Mechanical }}}
\end{gathered}
$$

Equivalent stress,

$$
\sigma_{i}=\sigma_{y}+\mathrm{E}_{p} \varepsilon_{i}^{p}
$$

Plastic Modulus,

$$
\mathrm{E}_{p}=\frac{\mathrm{E}_{t} \mathrm{E}}{\mathrm{E}-\mathrm{E}_{t}} \text {. }
$$

The thermal stress -strain relations can be written in terms of the stresses, the coefficient of thermal expansion $(\alpha)$.

$$
\begin{aligned}
\varepsilon_{r}= & \frac{1}{\mathrm{E}}\left(\sigma_{r}+2 \vartheta^{e} \sigma_{t}\right)+ \\
& \alpha \mathrm{T}+\varepsilon_{r}{ }^{p} \ldots \ldots \ldots \ldots(4) \\
\varepsilon_{t}= & \frac{1}{\mathrm{E}}\left\{\left(1-\vartheta^{e}\right) \sigma_{t}-\vartheta^{e} \sigma_{r}\right\}+ \\
& \alpha \mathrm{T}+\varepsilon_{t}^{p} \ldots \ldots(5) \\
\sigma_{r}= & \frac{\mathrm{E}}{\left(1+\vartheta^{e}\right)\left(1-2 \vartheta^{e}\right)}\left[\begin{array}{l}
\left.\left(1-\vartheta^{e}\right)\left(\varepsilon_{r}-\alpha \mathrm{T}-\varepsilon_{r}^{p}\right)\right] \ldots \ldots \\
+2 \vartheta^{e}\left(\varepsilon_{t}-\alpha \mathrm{T}-\varepsilon_{t}^{p}\right)
\end{array}\right] \\
\sigma_{t}= & \frac{\mathrm{E}}{\left(1+\vartheta^{e}\right)\left(1-2 \vartheta^{e}\right)}\left[\begin{array}{l}
\left(\varepsilon_{t}-\alpha \mathrm{T}-\varepsilon_{t}^{p}\right)+ \\
\vartheta^{e}\left(\varepsilon_{r}-\alpha \mathrm{T}-\varepsilon_{r}^{p}\right)
\end{array}\right] \ldots \ldots(
\end{aligned}
$$

Accordingly to satisfy the Mises yield criterion

$$
\sigma_{t}-\sigma_{r}=\sigma_{y}
$$

Centripetal temperature gradient are more appropriate for thermal Autofrettage than centrifugal thermal load. For centripetal Thermal Load if two regions or zones(inside plastic zone and outside elastic zone) are created with increasing the outer surface temperature, $\mathrm{T}_{\mathrm{O}}$ and keeping inside temperature $T_{i}$ fixed, then the stresses for centripetal flux satisfying the yield criterion for inner plastic zone, $\left(r_{i} \leq r \leq r_{c}\right)$ and outer region stresses will be in the elastic region $\left(r_{c} \leq r \leq r_{o}\right)$ If three regions are created with centripetal flux then three zones are created, first plastic region, $\left(r_{i} \leq r \leq r_{c}\right)$ middle elastic region $\left(r_{c} \leq r \leq r_{f}\right)$ and the outer plastic region $\left(r_{f} \leq r \leq r_{o}\right)$.
During combined (Thermal and Mechanical) loading behavior of residual stresses has been discussed in this work.

\section{FINITE ELEMENT METHOD}

A bilinear kinematic hardening quadratic axis symmetric 8 node elements have been considered for inelastic Finite Element (FE) analysis. The material properties used here, $\mathrm{E}=206 \mathrm{Gpa}, E_{t}=E_{t u}=10 \mathrm{GPa}, \sigma_{y}=850 \mathrm{MPa}$, and $\vartheta=0.3$, $\alpha=17.1 \times 10^{-6 \circ} \mathrm{C}$. The finite element 2-D model of sphere is constructed in ANSYS. Different combination of load is used for the result. For a spherical vessel with inner radii, $r_{i}=0.12 \mathrm{~m}$ and outer radii,$r_{o}=0.24 \mathrm{~m}$.

\section{RESULTS AND DISCUSSION}

The combined inner -surface pressurization and outer surface heating problem is far more complicated then either the inner surface pressurization problem or the yielding initiation portion of the outer-surface heating problem. In inner surface pressurization problem, the plastic region that start at the inner-surface and merely grows outward toward the outer surface as pressure increases until the entire shell has yielded [Fig.2]. For outer-surface heating, the yielding initiation behavior is identical to that of inner-surface pressure problem. However, for outer-surface heating, the plastic region cannot simply grow to encompass the total thickness of the spherical shell as it does for the inner surface pressurization problem [Fig.3]. With the combined loading we seeing some changes in yielding pattern of thermal loading and here mechanical loading pattern is dominating the thermal loading pattern [Fig.4]. Fig.4 shows the hoop stress distribution of thermo-mechanical load with fixed temperature gradient and different varying pressure. It is very clear with thermo-mechanical load yielding is start from inner radius and with increasing load grow towards outer-surface.

Fig. 5 shows the thermo-mechanical radial stress distribution with fixed temperature gradient and with different pressure load. Fig. 6 and 7 shows the residual thermo-mechanical radial and hoop stress behaviour respectively with increasing load keeping thermal load constant. Here with increasing load residual hoop stress near bore is less compressive and at the outer surface tangential hoop stress increase which loosing potential benefits of autofrettage. Fig. 8 shows the residual Thermo-mechanical hoop stresses distribution when pressure load is constant and gradually increasing temperature gradient keeping inside wall temperature constant. Here under a certain limit if we increase the temperature gradient residual hoop stress near inside radius is more compressive but after that limit if we increase thermal load keeping pressure load constant residual compressive hoop stress is decreasing or less compressive and yielding is start at outside radius it means its loosing benefits of autofrettage. Fig.9 shows the residual radial stress distribution keeping pressure load constant and gradually increasing temperature gradient. Here with increasing thermal load radial stress taking positive sign and it's also loosing benefits of autofrettage. 
So from last two conditions we can say that with some initial temperature gradient if we increase the pressure load the residual hoop and radial stress distribution pattern is similar with conventional mechanical autofrettage and we can obtain the required residual stress easily. Fig.10 shows the residual hoop and radial stress distribution with different radius ratio keeping thermo- mechanical load constant. Here with increasing radius ratio hoop stress near bore is less compressive and it's also decreasing positive hoop stress at outside radius. Fig.11 shows the radial and hoop stress distribution of different type of loading for same percentage of overstrain with radius ratio 2. Fig.12 shows the residual hoop stress and radial stress for different type of loading for same percentage of overstrain with radius ratio 2 . With same percentage of overstrain residual tangential stress near inside radius somewhat similar for both thermo-mechanical and thermal loading alone and in both case it is more compressive than mechanical loading, but at the outside radius positive tangential hoop stress is more for thermal loading alone then Thermo-mechanical loading and its reaches to the yield stress. In Fig.12 it is clear that with thermo- Mechanical load we are getting favorable residual stress distribution which is a improvement in autofrettage technique. Fig.13 showing how Bauschinger effect limits the benefits of autofrettage and how the residual hoop stresses changes with Bauschinger effect factor. Fig.14 shows the residual stress distribution of a Thermo-mechanical load with radius ratio 2 for elastic-perfectly plastic and strain hardening material. For strain-hardening sphere under Thermo-mechanical load prior to yielding at the inner surface radial stress and hoop stress differ by less than yield stress by definition of no yielding. Above the yield load (which ,incidentally, is identical to the yield load for elastic-perfectly plastic sphere), the radial stresses and hoop in the plastic region differ by more than yield stress for elastic -perfectly plastic material the stresses reduce for the case zero strain hardening or zero tangent modulus. For both type of material autofrettage with Thermo-mechanical load showing good agreement.

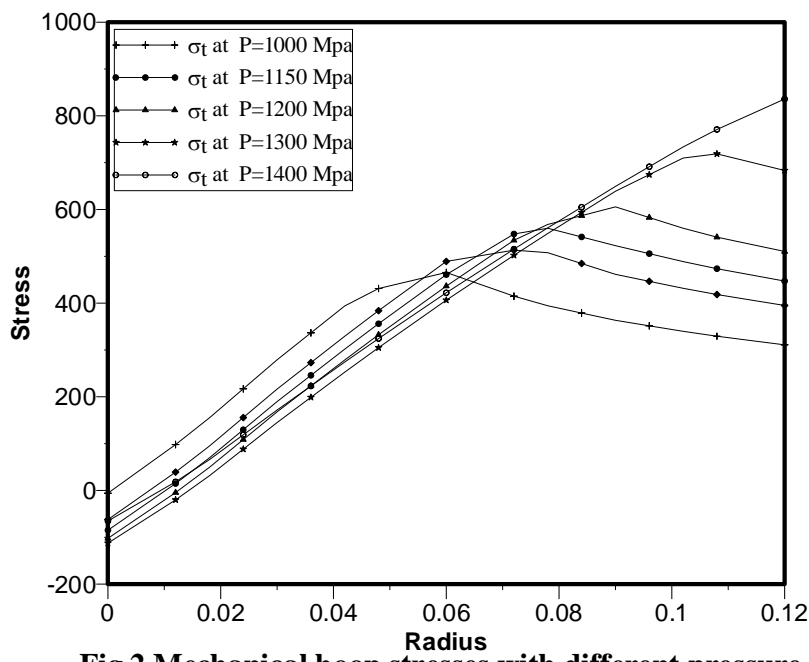

Fig.2 Mechanical hoop stresses with different pressure

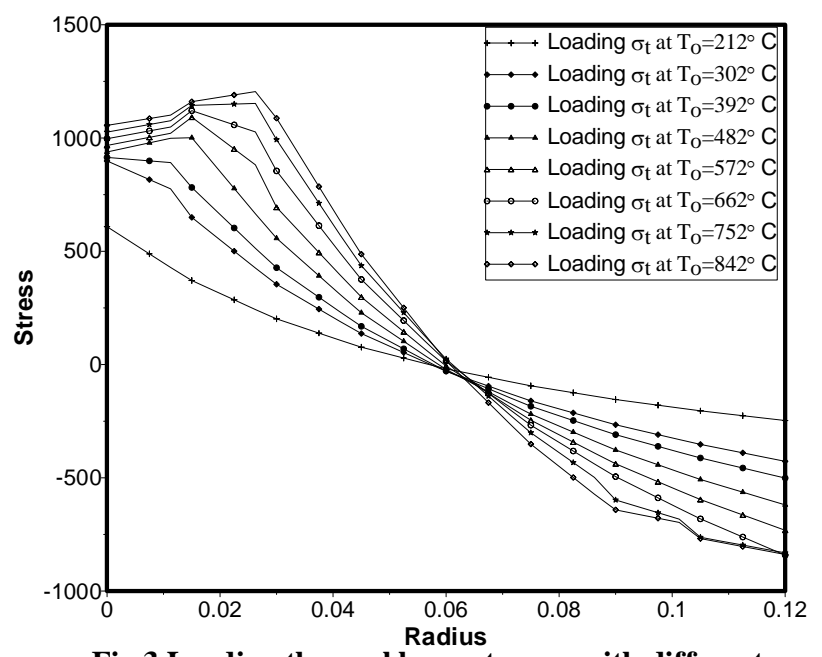

Fig.3 Loading thermal hoop stresses with different temperature gradient, $k=2$ and $T_{i}=41^{\circ} \mathrm{C}$

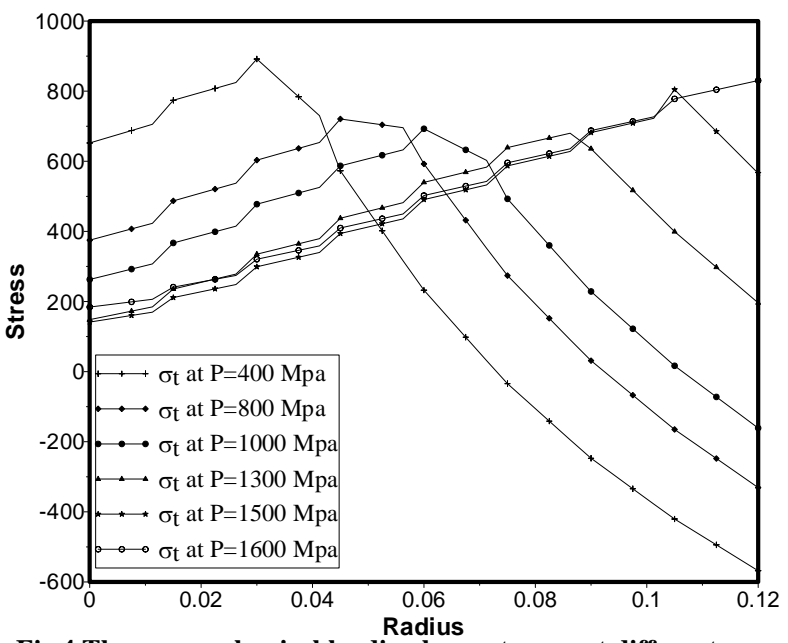

Fig.4 Thermo-mechanical loading hoop stresses at different pressure with same temperature gradient, $k=2, T_{0}=572^{\circ} \mathrm{C}$ and $\mathrm{T}_{\mathrm{i}}=41^{\circ} \mathrm{C}$

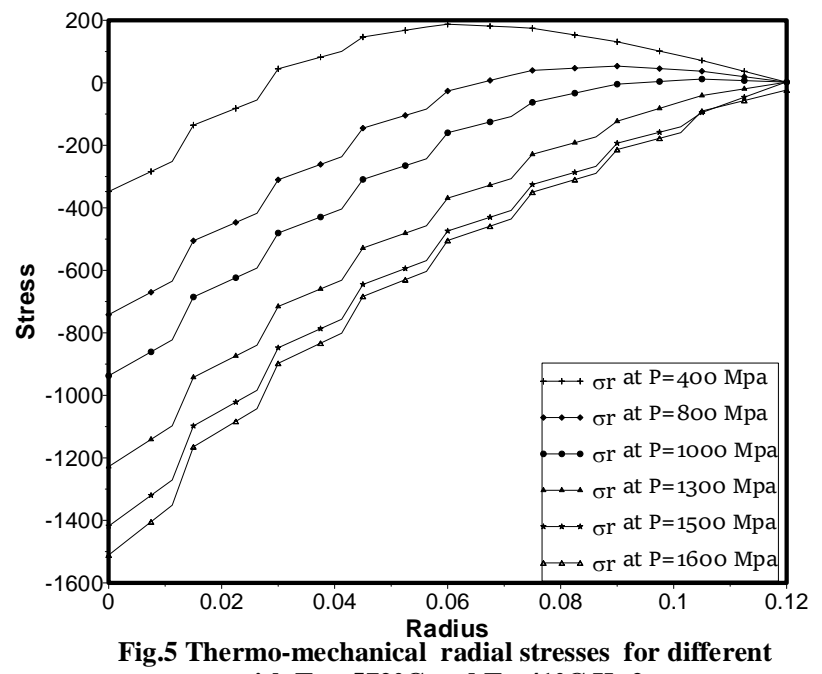
pressure with $\mathrm{T}_{0}=572^{\circ} \mathrm{C}$ and $\mathrm{T}_{\mathrm{i}}=41^{\circ} \mathrm{C}, \mathrm{K}=2$ 


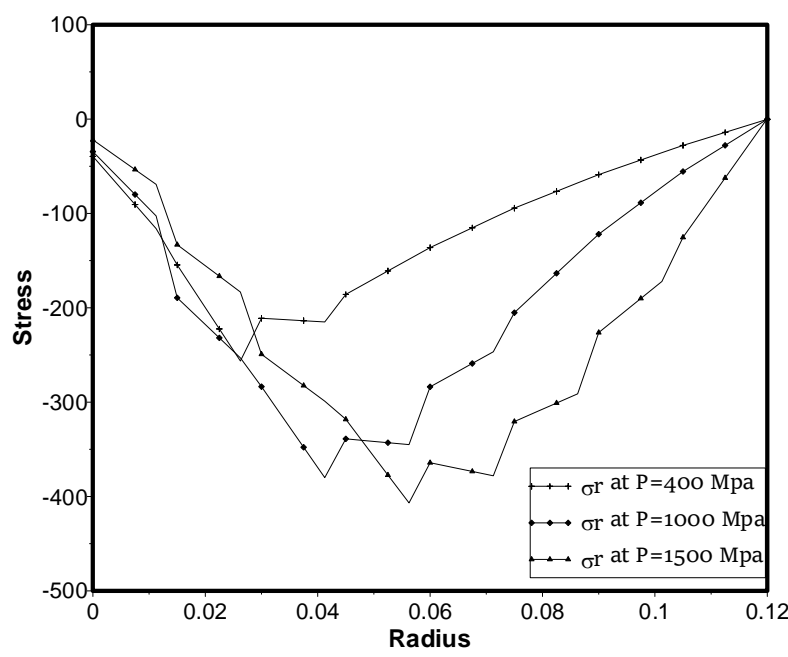

Fig.6 Residual thermo-mechanical radial stresses at different pressure with same temperature gradient, $k=2, T_{0}=572^{\circ} \mathrm{C}$

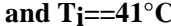

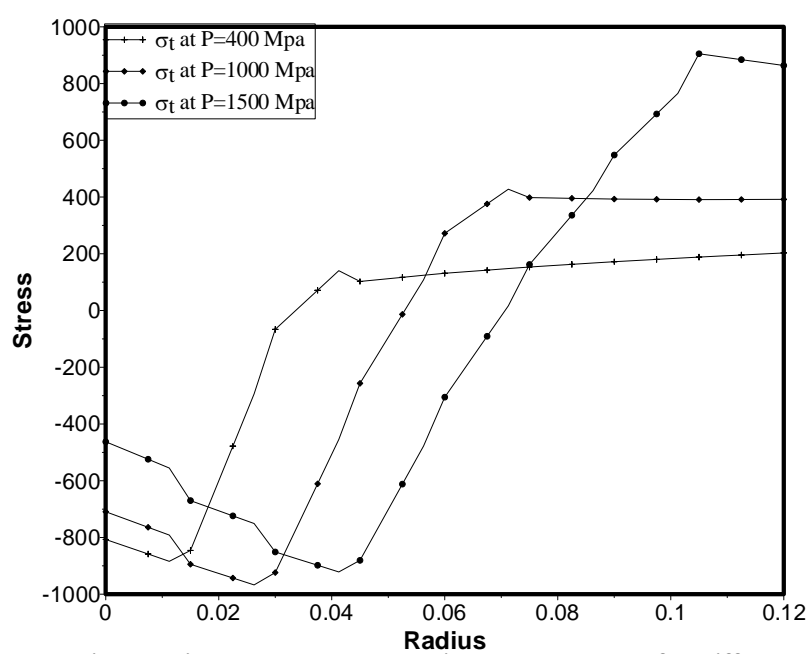

Fig.7 Residual thermo-mechanical hoop stresses for different pressure with same temperature gradient, $k=2, T_{0}=572^{\circ} \mathrm{C}$ and $\mathrm{T}_{\mathbf{i}}=41^{\circ} \mathrm{C}$

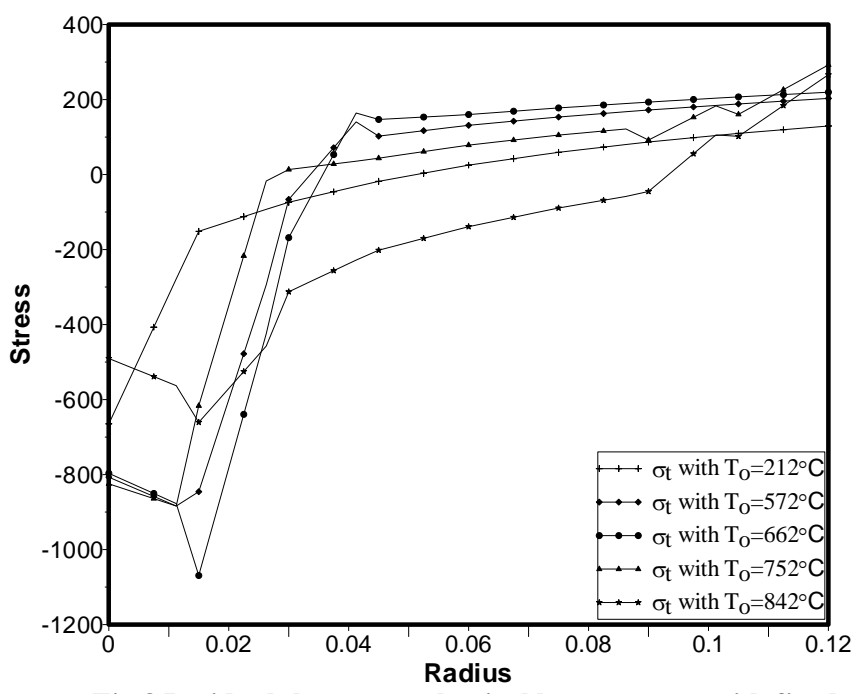

Fig.8 Residual thermo-mechanical hoop stresses with fixed pressure for different temperature gradient, $k=2, T_{i}=41^{\circ} \mathrm{C}$

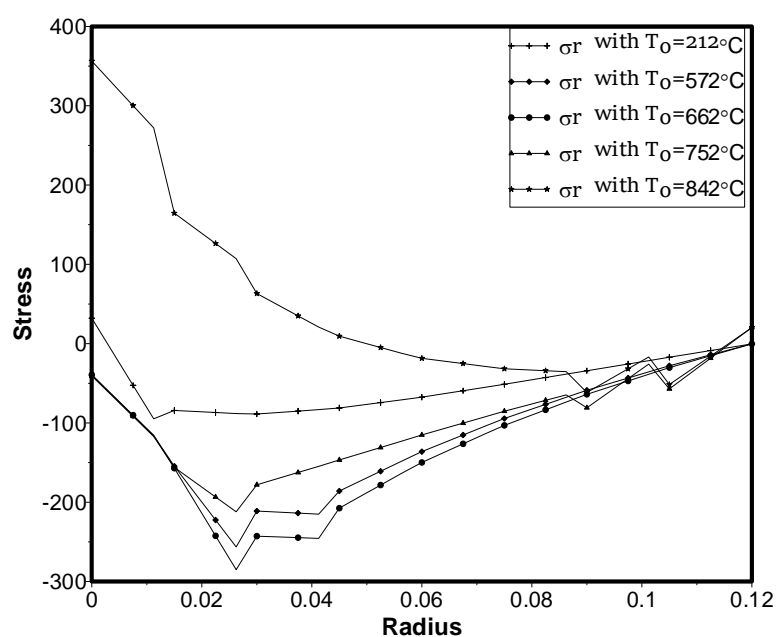

Fig.9 Residual thermo-mechanical radial stresses with fixed pressure $400 \mathrm{Mpa}$ for different temperature gradient, $\mathrm{k}=2$, $\mathrm{T}_{\mathbf{i}}=41^{\circ} \mathrm{C}$

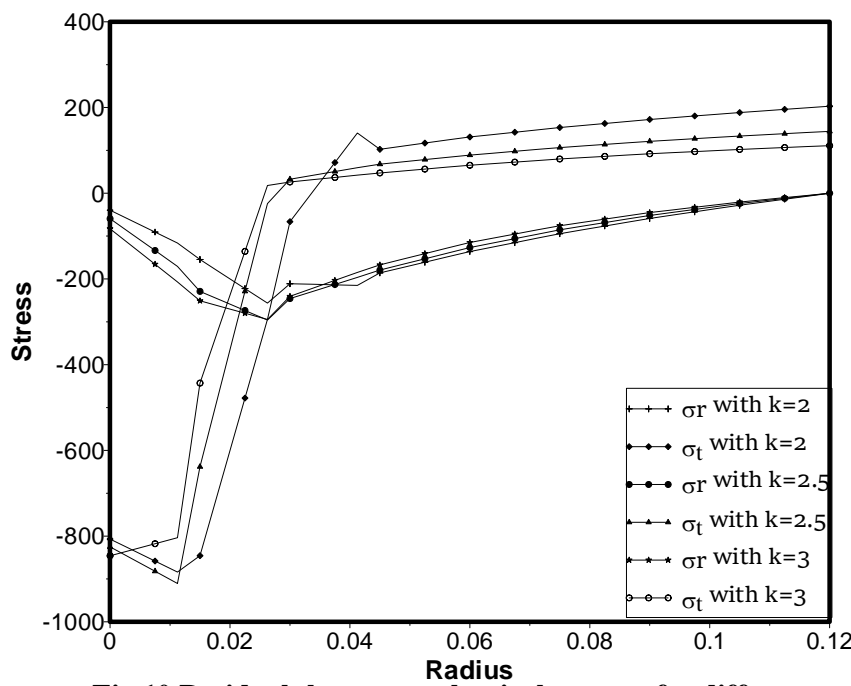

Fig.10 Residual thermo-mechanical stresses for different radius ratio with same temperature gradient and pressure, $\mathrm{P}=400 \mathrm{Mpa}, \mathrm{T}_{\mathrm{o}}=572^{\circ} \mathrm{C}$ and $\mathrm{T}_{\mathrm{i}}=41^{\circ} \mathrm{C}$

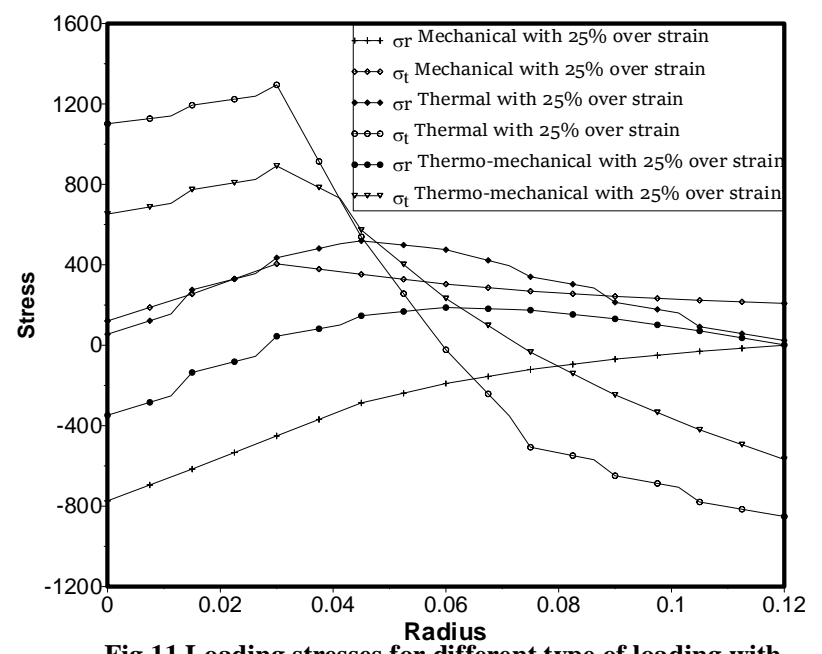

Fig.11 Loading stresses for different type of loading with $25 \%$ overstrain

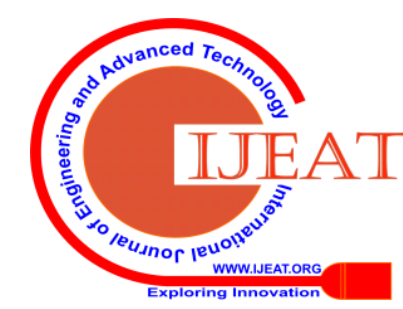




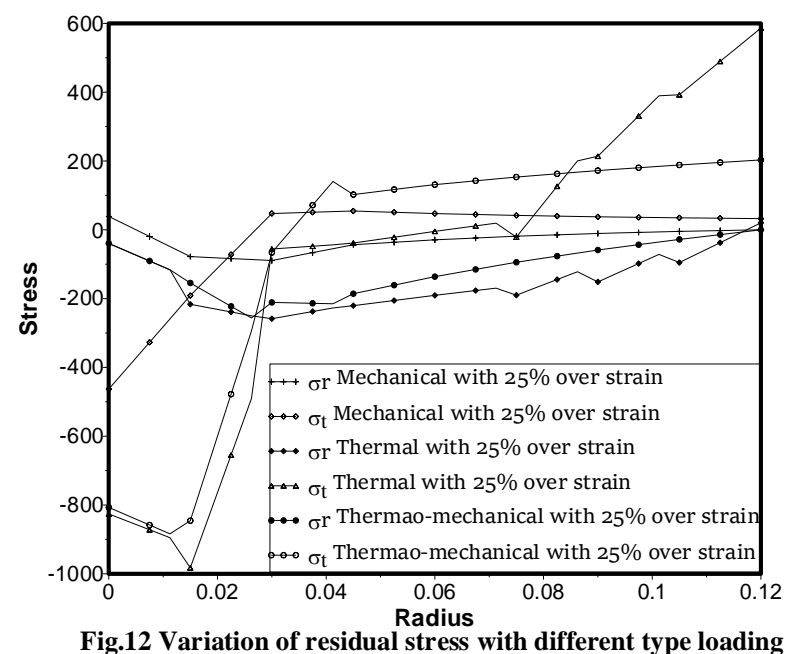

with $25 \%$ overstrain

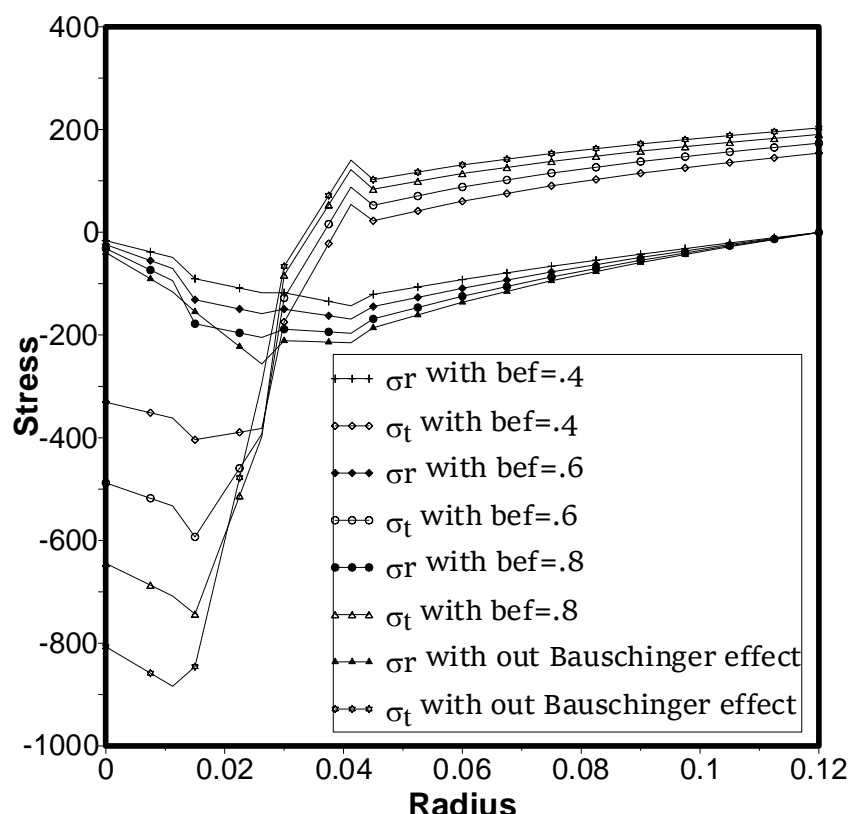

Fig.13 Residual thermo-mechanical stresses with different Bauschinger effect factor $k=2, P=400 \mathrm{Mpa}, \mathrm{T}_{0}=572^{\circ} \mathrm{C}$ and $\mathrm{T}_{\mathbf{i}}=\mathbf{4 1}{ }^{\circ} \mathrm{C}$

\section{CONCLUSION}

Autofrettage of sphere can also be created by Thermomechanical load. Autofrettage of sphere created by Thermomechanical load are more convenient and gives favorable stress distribution then mechanical load and thermal load. In Thermal loading If the temperature gradient exceeds some limit yielding at outside of the sphere, due to significant increase in tensile residual hoop stress at the outside diameter.

So we are not able to overstrain after some limit but with combined loading this problem we can minimize and can get identical yield initiation behavior to that for inner surface pressure. Plastic region simply continue to grow from inner-surface until the entire shell is plastic as in the collapse analysis for inner- surface pressurization. Mechanical load dominating combined gives more favorable stress distribution than thermal load dominating combined load. With combined load Yielding is initiate at very lower pressure than mechanical loading. Like residual mechanical and thermal stresses thermo-mechanical residual stresses are also extremely dependent on the Bauschinger effect and a large reduction in bore hoop stress due to the Bauschinger effect.

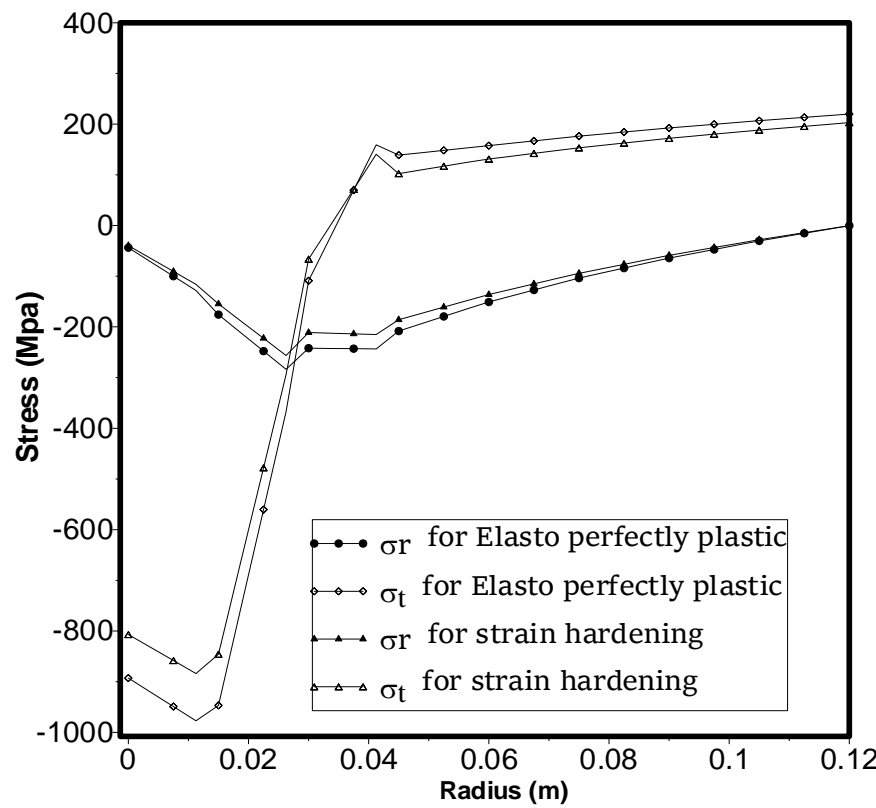

Fig.14 Residual thermo -mechanical stresses for different material model with same temperature gradient and same pressure, $\mathrm{P}=400 \mathrm{Mpa}, \mathrm{k}=2, \mathrm{~T}_{\mathrm{o}}=572^{\circ} \mathrm{C}$ and $\mathrm{T}_{\mathrm{i}}=41^{\circ} \mathrm{C}$

\section{REFERENCES}

1. Franklin, G. J. and Morrison, J. L.M., "Autofrettage of Cylinder :Prediction of Pressure, External Expansion Curves and Calculation of residual stresses", Proceeding of Institution of Mechanical Engineers,1960,Vol.174, PP.947-974.

2. Chen, P.T.C., "Stress and Deformation Analysis of Autofrettaged High Pressure Vessel", ASME special publication 110,Pressure vessel and Piping, New York: ASME United Engineering Centre, 1986, PP.61-70.

3. Chen, P.C.T., ,"Generalized Plane-Strain Problems in an Elastic-Plastic Thick-Walled Cylinder", In Transcripts of 26th Conference of Army Mathematicians,1980, PP.265-275.

4. Stacey, A and Webster, G.A., "Determination of Residual Stres Distributions in Autofrettaged Tubing", International Journal of Pressure Vessels and Piping, 1988,Vol.31,PP.205-220.

5. Chen P.C.T., "The Bauschinger and Hardening Effects on Residual Stresses in an Autofrettaged Thick-Walled Cylinder", Trans. ASME, Journal of Pressure Vessel Technology, 1986,Vol.108, PP.108-112.

6. Yu G., Chemical pressure vessel and piping and equipment, Beijing, Chemical Industrial Press, 1980

7. Harvey JF., Theory And Design Of Pressure Vessel, New York: Van Nostrand Reinhold Company Ltd., 1985.

8. Seung-Kee Koh,"Residual Stress Analysis of an External Grooved Thick- Walled Pressure Vessel",KSME Journal,1992,vol.7,No.3,PP. 194-202.

9. Jahed H., Sethuraman R. and Dubey R.N., " A Variable Materia Property Approach For Solving Elastic-Plastic Problems", Int. J. Pressure vessel and piping,1996, Vol 71,PP.285-291.

10. Jahed and Dubey,'An Axissymmetric Method Of Elastic-Plastic Analysis Capable Of Predicting Residual Stress Field", Journal of Pressure vessel Technology,1997,Vol.119,PP.264-273.

11. Lazzarin and Livieri ,"Different Solution For Stress And Strain Field In Autofrettaged Thick Walled Cylinder", International Journal of Pressure vessels and piping,1997,vol.31,PP.231-238.

12. R Zhu and J. Yang, "Autofrettaged Of Thick Cylinder", Int. J. of Pressure Vessel and Piping,1998,vol.75,PP.443-446.

13. Anthony. P. Parker ,"Autofrettage of open-end tubes-Pressures, Stresses, Strains and Code Comparisons" ,Journal of Pressure Vessel Technology,2001,vol.123.PP.271-281. 
14. Paolo Livieri and Paolo Lazzarian, "Autofrettage Cylindrical vessels and Bauschinger Effect: An analytical Frame for Residual stress Distribution", 2002, Journal of pressure vessel Technology,vol.124,PP.38-46.

15. H. Jahed And G. Ghanbari," Actual Unloading Behavior And Its Significance On Residual Stress In Mechanical Autofrettaged Tube", Journal Of Pressure Vessel Technology,2003,Vol.125,PP.321-325.

16. X. P Huang and W. C .Cui, "Effect of Bauschinger Effect and Yield criterion on Residual Stress Distribution of Autofrettaged Tube", Journal Of Pressure Vessel Technology,2006, vol.128,PP.212-216.

17. C. Levy, M. Perl, And S. Kotagiri, "The Bauschinger Effect's Influence On The Sifs Of Multiple Longitudinal Coplanar Cracks In Autofrettaged Pressurized Cylinders" ,Engineering Fracture Mechanics,2006,Vol.73, Pp.1814-1825.

18. Gibson ,A. Hameed, Parker A.P. and J.G. Hetherington," A Comparison Of Method For Predicting Residual Stresses In Strain -Hardening ,Autofrettaged thick Cylinders Including The Bauschinger Effect", J. of Pressure vessel Technology,2006,vol.128,PP.217-222.

19. R. Adibi- Asl and P.Livieri, "Analytical Approach In Autofrettaged Spherical Pressure Vessels Considering The Bauschinger Effect", Journal of pressure vessel technology,2007,vol.129,PP.411-419.

20. M.H. Hojjati and A. Hossani, "Theoretical And Finite- Element Modeling Of Autofrettage Process In Strain- Hardening Thick Walled Cylinders" , International Journal Of Pressure Vessel And Piping, 2006, Vol.84, PP.310-319.

21. X. Huang And T. Moan, "Residual Stress In An Autofrettaged Tube Taking Bauschinger Effect As A Function Of The Prior Plastic Strain ", Journal Of Pressure Vessel Technology,Vol.131,PP.021207-1-7.

22. Anthony P. Parker."A Re-autofrettage procedure for Mitigation of Bauschinger Effect in thick cylinder", Journal of Pressure vessel Technology,2004,vol.126,PP.451-454.

23. Hamid Jahed, Babak Ahmadi Moghadam and Mojtaba Shambooli, "Re-Autofrettage", Journal Of Pressure Vessel Technology,2006,vol.128,PP.223-226.

24. A.P. Parker and X. Huang, "Autofrettage and Reautofrettage of spherical vessel",Journal Of Pressure Vessel Technology, 2007, vol. 129,PP.83-88.

25. S.-k. Koh and E.-G. Na, "Fatigue Crack Groth Life Of Thick- Walled Cylinders With An External Radial Crack", International Journal of Fatigue,1999,vol.21,PP.135-146

26. S.-K. Koh,"Fatigue analysis of autofrettaged pressure vessels with radial holes", Int. J. of Fatigue,2000,vol.22,PP.717-726.

27. R. Thumser,J.W.Bergmann and M. Vormwald,"Residualstress Fields And Fatigue Analysis Of Autofrettaged Parts", Int. J. Of Pressure Vessel And Piping,2002,vol.79,PP.113-117.

28. Hamed Jahed, Behrooz Farshi and Mohammad Hosseini, "Fatigue life prediction of autofrettage tubes using actual material behaviour", Int. J. Of Pressure Vessel And Piping,2006,vol.83,PP.749-755.

29. Hamed Jahed, Behrooz Farshi and Mohammad Hosseini,"The Actual Unloading Behavior Effect On Thermo-Mechanical Stress Intensity Factor And Life Of Autofrettage Tube", Int. J of Fatigue,2007,vol.29,PP.360- 369.

30. S.M. Nabavi and A.R. Shahani, "Thermal Stress Intensity Factors For A Cracked Cylinder Under Transient Thermal Loading", Int. J. Of Pressure Vessel And Piping,2009,vol.86,PP.153-163.

31. B. A. Boley and J. H. Weiner, Theory of Thermal Stressses, New York: John Wiley, 1960.

32. S.P. Timoshenko and J.N. Goodier, Theory of Elasticity, Mc Graw Hill, India,.2017.

33. J. Chakrabarty, Theory Of Plasticity,Elsevier Butterworth-H Einemann, 2006

34. S.M. Kamal and U. Dixit,"Feasibility Study Of Thermal Autofrettage Of Thick-Walled Cylinders" ,Journal Of Pressure Vessel Technology, 2015,vol.137,PP.1-7.

35. Rupali, S. C. Mondal, S. Sarkar,2017"Analytical and finite element analysis of thermal autofrettage process in spherical vessel",IOSR Journal of Mechanical and Civil Engineering,vol.14,Issue 3,Ver II,PP.10-16.

\section{NOMENCLATURE}

$\begin{array}{ll}r_{o} & : \text { Radius } \\ r_{i} & : \text { Outside Radius } \\ r_{c} & : \text { Loading first yield radius } \\ r_{f} & : \text { Loading second yield radius } \\ r_{d} & : \text { Unloading yield radius } \\ T_{o} & : \text { Outside temperature } \\ \mathrm{T}_{i} & : \text { Inside temperature } \\ \varepsilon & : \text { Strain (Deformation) } \\ \sigma_{t}, \sigma_{r}, \sigma_{\phi} & : \text { Stresses in Principal Direction. } \\ \varepsilon_{t}, \varepsilon_{r}, \varepsilon_{\phi} & : \text { Strain in Principal Direction. } \\ \sigma_{i} & : \text { Equivalent stress } \\ \varepsilon_{i} & : \text { Equivalent strain } \\ \sigma_{r} & : \text { Radial stress } \\ \sigma_{t} & : \text { Hoop stress, } \\ \vartheta & : \text { Poisson's ratio } \\ \mathrm{E}_{t} & : \text { Loading Tangent Modulus } \\ \mathrm{E}_{t u} & : \text { Unloading Tangent Modulus } \\ \mathrm{E}_{p} & : \text { Modulus of plasticity } \\ u & : \text { Displacement } \\ & \end{array}$

\section{AUTHORS PROFILE}

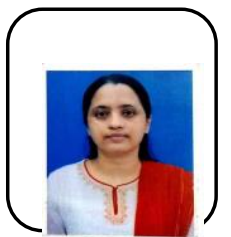

Rupali has received Diploma degree in Mechanica Engineering from Malda Polytechnic ,West Bengal, India and holds a BE degree in Mechanica Engineering from C.V. Raman College of Engineering, Bhubneswar, Odisha, India. She has received MME Degree with Machine Design specialization from Jadavpur University, kolkata, India. After that She received Ph. D degree from Jadavpur University, kolkata, India. She is an Assistant Professor in Mechanical Engineering Department, Dr. B. C. Roy Engineering College, Durgapur. Her current research areas Pressure Vessel Design and Structural stress analysis. She is a Corporate Member of Institution of Engineers (India) and holds Chartered Engineer Certificate. She has six publications in International Journals and three in International / National Conferences. 